\title{
SISTEM PAKAR DIAGNOSA KERUSAKAN KAMERA DSLR BERBASIS ANDROID
}

\author{
1) Aprih Widayanto, ${ }^{2)}$ Dany Pratmanto, ${ }^{3)}$ Sahal Tsani Musyaffa \\ 1) Sistem Informasi, STMIK Nusa Mandiri Jakarta \\ aprih.apz@nusamandiri.ac.id \\ 2) Sistem Informasi, STMIK Nusa Mandiri Jakarta \\ dany.dto@nusamandiri.ac.id \\ 3) Teknik Informatika, AMIK BSI Purwokerto \\ sahalcinong@gmail.com
}

\begin{abstract}
The development of science and technology makes people interested in creating new things. with the utilization of information and communication technology by means of the application form are combined into knowledge. One of these experts about the world of dslr camera-based mobile. This expert system method using Forward Chaining using the base database compiled into various tables in an order so that a user can retrieve and expert conclusions from what has been diagnosed by an expert system. Application of expert system tool was created as a user and expert in diagnosing damage of dslr camera from the analysis according to a practitioner and internet media. Expert system will feature questions that will then be selected and answered by users until the program to find a solution of the diagnosis has been done on this expert system. In addition this expert system is equipped with information to damage ds/r camera, the way of handling, and how to care ds/r camera.
\end{abstract}

\section{Keywords: Expert System, Damage Dslr Camera, Forward Chaining}

Abstrak - Berkembangnya ilmu pengetahuan dan teknologi membuat orang tertarik untuk menciptakan hal-hal baru. dengan pemanfaatan teknologi informasi dan komunikasi dengan cara digabungkan menjadi bentuk aplikasi pengetahuan. Salah satunya pakar tentang dunia kamera dslr berbasis mobile. Sistem pakar ini menggunakan metode Forward Chaining dengan menggunakan basis database yang disusun kedalam berbagai tabel dalam suatu aturan agar seorang pakar dan penggunadapat mengambil kesimpulan dari apa yang sudah didiagnosa oleh sistem pakar ini. Aplikasi sistem pakar ini dibuat sebagai alat bantu seorang pakar dan pengguna dalam mendiagnosa kerusakan kamera dslr dari analisa menurut seorang praktisi dan media internet. Sistem pakar ini akan menampilkan pertanyaan yang kemudian akan dipilih dan dijawab oleh pengguna sampai program menemukan solusi dari diagnosa yang telah dilakukan pada sistem pakar ini. Selain itu sistem pakar ini dilengkapi dengan informasi kerusakan kamera dsır, cara penanganan, dan cara perawatan kamera dsır.

\section{Kata Kunci: Sistem Pakar, Kerusakan Kamera DsIr, Forward Chaining}

\section{A. PENDAHULUAN}

Berkembangnya ilmu pengetahuan dan teknologi membuat orang tertarik untuk menciptakan hal hal yang baru agar lebih berguna dimasa yang akan datang. Teknologi informasi dan komunikasi berbasis smartphone dari waktu ke waktu berkembang sangat pesat. $\mathrm{Hal}$ ini ditandai dengan adanya pengembangan pada hadware dan software.Sistem operasi Apple's OS, Android, Windows phone, Blackberry OS, Symbian OS merupakan pengembangan dari segi software yang dibutuhkan untuk mengelola dan mengatur berbagai macam aplikasi dan fitur yang bekerja pada smartphone secara multitasking dan tidak saling mengganggu sama lain. Sehingga fungsi dari smartphone lebih maksimal. Seiring berjalannya waktu kebutuhan masyarakat erhadap smartphone semakin meningkat. Hal ini menyebabkan para pengembang smartphone semakin berlombalomba untuk membuat suatu inovasi baru yang mampu memenuhi kebutuhan dan meningkatkan produktivitas masyarakat.

Dalam dunia fotografi, kamera mempunyai arti penting dalam kehidupan sehari-hari terutama bagi photografer di Indonesia, karena kamera dslr dijadikan sebagai alat pokok dalam pekerjaan. Semakin sering pemakaian pada kamera maka semakin dekat dengan kerusakan hadware atau software. Terbatasnya sumber daya manusia pakar kamera dsIr dan masih banyak yang belum mempunyai pengetahuan yang memadai untuk bisa menggantikan fungsi sebagai seorang pakar menjadi kendala yang masih banyak dilapangan. Selain itu, karena data data penelitian yang belum tersimpan dalam sistem terkomputerisasi. Hal ini sangat menyita waktu sehingga tidak efisien dalam mengatasi 
permasalahan kamera. Untuk membantu mengatasi hal tersebut penulis melakukan penelitian dan memberi alternatif dengan membuat sebuah aplikasi yang dapat mengidentifikasi kerusakan kamera dengan menggabungkan kemampuan seorang pakar kedalam aplikasi mobile berbasis android yang disebut dengan sistem pakar.

\section{B. TINJAUAN PUSTAKA}

Menurut Hayadi (2016:1) "Sistem pakar adalah suatu aplikasi computer yang ditujukan untuk membantu pengambilan keputusan atau pemecahan persoalan dalam bidang yang spesifik". Menurut Rosnelly (2012:2) menyatakan bahwa "sistem pakar adalah sistem komputer yang ditujukan untuk meniru semua aspek (emulate) kemampuan pengambilan keputusan (decision making) seorang pakar".

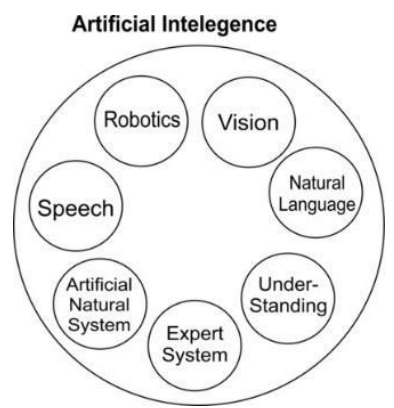

\section{Gambar 1. Artificial Intelligence}

Sistem pakar memanfaatkan secara maksimal pengetahuan khusus selayaknya seorang pakar untuk memecahkan masalah. Pakar atau ahli (ekspert) didefinisikan sebagai seorang yang memiliki pengetahuan atau keahlian khusus yng tidak dimiliki oleh kebanyakan orang. Seorang pakar dapat memecahkan masalah yang tidak mampu dipecahkan kebanyakan orang. Dengan kata lain dapat memecahkan suatu masalah dengan lebih efisien. Pengetahuan yang dimuat kedalam sistem pakar dapat berasal dari seorang pakar ataupun pengetahuan yang berasal dari buku, jurnal, majalah dan dokumentasi yang dipublikasikan lainnya, serta orang yang memiliki pengetahuan meskipun bukan ahli. Istilah sistem pakar (expert system), sering disinonimkan dengan sistem berbasis pengetahuan (knowledge based system) atau sistem pakar berbasis pengetahuan (knowledge based expert system).

Kelebihan sistem pakar menurut Rosnelly (2012:5) adalah:

1. Meningkatkan ketersediaan (increased availability). Kepakaran atau keahlian menjadi tersedia dalam sistem komputer. Dapat dikatakan bahwa sistem pakar merupakan produksi kepakaran secara masal (massproduction).
2. Mengurangi biaya (reduced cost). Biaya yang diperlukan untuk menyediakan keahlian per satu orang user menjadi berkurang.

3. Mengurangi bahaya (reduced danger). Sistem pakar dapat digunakan dilingkungan yang mungkin berbahaya bagi manusia.

4. Permanen (permanence). Sistem pakar dan pengetahuan yang terdapat di dalamnya bersifat lebih permanen dibandingkan manusia yang dapat merasa lelah, bosan, dan pengetahuannya hilang saat sang pakar meninggal dunia.

5. Keahlian multipel (multiple expertise). Pengetahuan dari beberapa pakar dapat dimuat ke dalam sistem dan bekerja secara simultan dan kontinyu menyelesaikan suatu masalah setiap saat. Tingkat keahlian atau pengetahuan yang digabungkan dari beberapa pakar dapat melebihi pengetahuan satu orang pakar.

6. Meningkatkan kehandalan (increased reliability). Sistem pakar meningkatkan kepercayaan dengan memberikan hasil yang benar sebagai alternatif pendapat dari seorang pakar atau sebagai penengah jika terjadi konflik antara beberapa pakar. Namun hal tersebut tidak berlaku jika sistem dibuat oleh salah seorang pakar, sehingga akan selalu sama dengan pendapat pakar tersebut kecuali jika sang pakar melakukan kesalahan yang mungkin terjadi pada saat tertekan atau stres.

Sedangkan kelemahan sistem pakar menurut Hayadi (2016:3) adalah:

1. Biaya yang sangat mahal untuk membuat dan memeliharanya.

2. Sulit dikembangkan karena keterbatasan keahlian dan ketersediaan pakar.

3. Sistem pakar tidak $100 \%$ bernilai benar.

Ciri-ciri sistem pakar menurut Hayadi (2016:3) adalah :

1. Terbatas pada domain keahlian tertentu

2. Dapat memberikan penalaran untuk data yang tidak pasti

3. Dapat mengemukakan rangkaian alasan yang diberikannya dengan cara yang dapat dipahami.

4. Berdasarkan pada kaidah atau rule tertentu.

5. Dirancang untuk dapat dikembangkan secara bertahap.

6. Pengetahuan dan mekanisme inferensi jelas terpisah.

7. Keluarannya bersifat anjuran

8. Sistem dapat mengaktifkan kaidah secara searah yang sesuai yang dituntun oleh dialog dengan pemakai. 
Menurut Hayadi (2016:7) "ada dua teknik inferensi yaitu pelacakan kebelakang (Backward Chaining) dan pelacakan kedepan (Forward Chaining)".

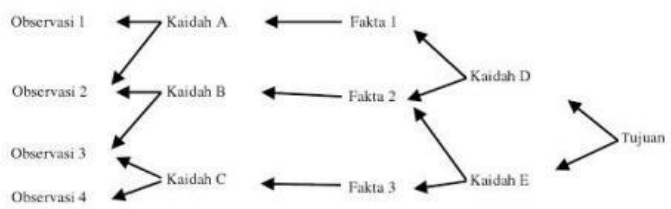

Sumber : Hayadi (2016:8)

Gambar 2. Diagram pelacakan ke belakang (Backward Chaining)

Pelacakan ke belakang (Backward Chaining) dengan cara memulai penalaran dari kesimpulan hipotesa menuju fakta yang mengandung hipotesa tersebut.

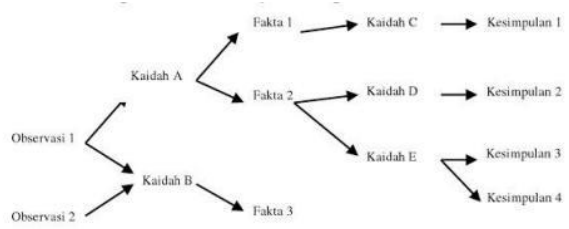

Sumber: Hayadi (2016:7)

Gambar 3. Diagram pelacakan ke depan (Forward chaining)

Pelacakan ke depan (Forward Chaining) merupakan kebalikan dari pelacakan kebelakang yaitu memulai dari sekumpulan data menuju kesimpulan. Kedua metode inferensi tersebut dipengaruhi oleh tiga macam teknik penelusuran yaitu :

1. Depth-first search melakukan penelusuran kaidah secara mendalam dari simpul akar bergerak menurun ketingkat dalam yang berurutan.

2. Bread-firs search bergerak dari simpul akar, simpul yang ada pada setiap tingkat diuji sebelum pindah ketingkat selanjutnya.

3. Best-first search bekerja berdasarkan kombinasi kedua metode sebelumnya.

\section{METODE PENELITIAN}

Metode yang digunakan dalam membuat aplikasi adalah menggunakan metode forward chaining, dimana metode ini adalah suatu penalaran yang dimulai dari fakta untuk mendapatkan kesimpulan dari fakta tersebut.

\section{HASIL DAN PEMBAHASAN}

Berdasarkan penelitian kerusakan kamera dsIr berikut adalah data-data kerusakannya:

1. Data kerusakan kamera canon dsIr

a) Kerusakan kontak elektrik antara lensa dengan body

Gejala:

1) Kamera bisa hidup

2) Lensa tidak berfungsi
3) Saat digunakan memotret muncul (Commu nication between the camera and lensis faulty. Clean contact)

Penyebab:

1) Kontak elektronik antara lensa dengan body kotor, basah, atau rusak

2) Suhu yang dingin atau lembab membuat sirkuit basah

Penanganannya:

1) Matikan kamera, kemudian lepas lensa dari body kamera

2) Bersihkan kontak elektronik menggunakan kain atau tisu bersih

3) Jangan menggunakan tisu basah maupun air

4) Kemudian pasang kembali lensanya, dan cobalah untuk memotret

b) Kerusakan pada kartu memory

Gejala:

1) Kamera bisa dinyalakan

2) Saat digunakan memotret muncul (Card cannot be accesed. Reinsert/ change card or format card with camera)

Penyebab:

a) Kartu memori rusak sehingga sistem tidak dapat membaca memory

b) Kontak elektrik pada memory kotor

Penanganannya:

a) Matikan kamera

b) Lepas kartu memory

c) Bersihkan kontak elektrik pada memory menggunakan penghapus pensil

d) Pasang kembali

e) Jika hal tersebut masih terjadi maka format kartu memory dari kamera langsung atau ganti memory

f) Jika masih belum berhasil maka bawakan ke tukang servis kamera dslr

c) Terlalu banyak folder pada memory

Gejala:

1) Kamera bisa dinyalakan

2) Saat digunakan memotret muncul (There are too many folder on the memory card)

Penyebab:

1) Terlalu banyak folder pada memory

Penanganannya:

1) Hidupkan kamera

2) Masuk ke menu pada kamera cari menu setting

3) Kemudian cari format memory, setelah itu format, matikan dan nyalakan kembali

d) Kartu memory penuh

Gejala:

1) Kamera bisa dinyalakan

2) Saat digunakan memotret muncul (Cannot save images because card is full, Replace card) 
Penyebab:

1) Ruang penyimpanan pada kartu memory sudah penuh

2) Sehingga tidak bisa menyimpan data atau file gambar

Penanganannya:

1) Nyalakan kamera

2) Hapus beberapa foto yang tidak penting

3) Atau format kartu memory alangkah baiknya ganti dengan kartu memory cadangan

e) Kerusakan pada Flash internal

Gejala:

1) Kamera bisa dinyalakan

2) Flash internal tidak dapat digunakan,tidak bisa dibuka secara mode otomatis atau manual

3) Tombol pembuka flash internal tidak berfungsi pada mode manual

Penyebabnya:

1) Tombol pembuka flash internal tidak berfungsi atau rusak

2) Lampu LED pada flash rusak

3) Kondisi pencahayaan terlalu over sehingga flash secara otomatis tidak bisa membuka karena kondisi cahaya terang

Penanganannya:

1) Coba untuk clear all setting pada kamera anda

2) Jika menggunakan mode otomatis arahkan pemotretan ke tempat gelap, maka flash akan otomatis membuka.

f) Kerusakan pada Sensor

Gejala:

1) Kamera bisa dinyalakan

2) Hasil gambar tidak maksimal (Blur)

3) Saat digunakan memotret muncul (Sensor cleaning is not possible. Turn the camera off and on again)

Penyebanya:

1) Sensor kotor

2) Sensor cleaning tidak berfungsi normal

Penanganannya:

1) Matikan kamera, maka sensor cleaning secara otomatis akan bekerja

2) Jika tidak maka kita bersihkan sensor secara manual melalui menu setting pada kamera kemudian pilih cleaning sensor

3) Jika hasil pemotretan masih belum maksimal maka kita cek settingan bukaan pencahayaan, diafragma dll. pada mode manual.

4) Jika sudah benar dan dan hasil masih sama silahkan bawa kamera ketukang servis kamera dslr

\section{Data kerusakan kamera nikon dslr}

a) Koneksi elektronis mengandung minyak Gejala:

1) Kamera bisa dinyalakan

2) Lensa tidak berfungsi saat digunakan

3) Saat digunakan memotret muncul pesan "Err" yang berkedip

Penyebab:

1) Menunjukan adanya fungsi kamera yang tidak normal

2) Koneksi elekronisnya mengandung minyak dari proses manufakturing

Penanganan:

1) Matikan kamera

2) Lepas lensa dan bersihkan kontak elektrik antara kamera dan lensa dengan kain halus dan kering

3) Kalau pesan "Err" masih muncul maka coba lepas baterai lalu pasang kembali

b) Kerusakan pada ring aperture

Gejala:

1) Kamera bisa dinyalakan

2) Saat digunakan muncul pesan "FEE" berkedip

Penyebab:

1) Biasanya pesan ini muncul pada pemakaian lensagenerasi tua yang dilengkapi ring aperture dan ring tersebut tidak diset diposisi aperture minimum.

2) Saat mengganti lensa, mungkin secara tidak sengaja memutar ring aperture pada lensa, sehingga memicu pesan error.

Penanganan:

1) Memutar ring aperture pada posisi "f" pada angka terbesar (bukan minimum), seperti f/16 pada lensa

c) Kerusakan pada kontak elektrik lensa

Gejala:

1) Kamera bisa dinyalakan

2) Saat digunakan muncl pesan segitiga dengan huruf " $f$ ".

Penyebab:

1) Kamera tidak mendeteksi adanya kerusakan

Penanganan:

1) Lepas lensa dari body kamera

2) Bersihkan kontak elektrik lensa

3) Pasang dan pastikan lensa terpasang dengan benar

d) Kerusakan pada memory card

Gejala:

1) Kamera bisa dinyalakan

2) Saat digunakan memotret muncul pesa "-E-" terus menerus

Penyebab:

1) Kartu memory sudah tidak layak pakai

2) Kartu memory rusak

Penanganan: 
1) Cek apakah kartu memory sudah terpasang

2) Coba untuk pasang memory card lain

3) Atau format kartu memory langsung dari kamera

4) Jika masih saja muncul maka bisa dari koneksi dudukan memory yang rusak, karena sering masuk keluar memory (kaki slot memory patah)

5) Bawalah ke tukang servis kamera

e) Kerusakan pada memory

Gejala:

1) Kamera bisa dinyalakan

2) Saat digunakan muncul pesan "CHA/CHR" berkedip

Penyebab:

1) Biasanya terjadi pad saat mengimport foto dari memory ke komputer

2) Lalu menghapus data pada memory dari komputer

3) Menghapus file tanpa memformat bukanlah cara yang tepat

Penanganan:

1) Format kartu memory langsung dari kamera

f) Jamur lensa

Gejala:

1) Kamera bisa dinyalakan

2) Saat digunakan terdapat gambar seperti kotoran pada lensa

3) Dan seperti ada bercak lecet didalam lensa

Penyebab:

1) Penyimpanan kamera atau lensa tidak sesuai prosedur

2) Menyimpan pada tingkat kelembaban tinggi

\section{Cara perawatan kamera dslr}

a) Simpan kamera ditempat yang kering dan tidak terkena sinar matahari langsung.

b) Simpan kamera dan lensa pada drybox atau dry cainet sehingga kita bisa mengonrol tingkat kelembaban atau cara alternatifnya menggunakan silica gel.

c) Periksa sensor kamera setelah pemakaian, bila ada kotoran pada sensor maka segera bersihkan sensor dari debu menggunakn blower pembersih khusus.

d) Hindari penggantian lensa diluar ruangan yang tigkat debunya banyak.

e) Jika ada beberapa komponen tidak berfungsi ada baiknya jangan dipaksakan untuk bekerja, bawalah ketukang servis.

f) Jika sudah selesai pemakaian ada baiknya kamera langsung dibesihkan dan disimpan untuk menghindari terjadinya jamur.

g) Hindari meninggalkan kamera pada mobil terlalu lama pada saat mobil terkena sinar matahari langsung, karena rentan terhadap suhu lembab yang tinggi. h) Pakai strap kamera supaya kamera tidak gampang jatuh dari tangan

i) Matikan kamera sebelum mengganti lensa, memory dll.

j) Bersihkan kontak lensa dengan microfiber

k) Baterai lithium-lion biasanya bertahn hanya 500 kali charger, dan ada baiknya dalam pembuangan sampah baterai jangan sembarangan buang, buanglah ketempat khusus.

I) Jauhkan kamera dari air, kecuali sudah memakai waterproof

\section{Analisa Sumber Data}

Berdasarkan data yang peneliti dapat, peniliti membuat database dengan isi dua tabel yaitu tabel gejala dan kerusakan:

Tabel. 1. Tabel Gejala

\begin{tabular}{|c|l|l|l|l|l|}
\hline No & $\begin{array}{l}\text { Element } \\
\text { data }\end{array}$ & Akronim & Tipe & Panjang & Keterangan \\
\hline 1 & Id Gejala & idgejala & INT & 2 & $\begin{array}{l}\text { Primary } \\
\text { key }\end{array}$ \\
\hline 2 & $\begin{array}{l}\text { Nama } \\
\text { Gejala }\end{array}$ & namagejala & TEXT & 169 & \\
\hline 3 & ya & Ya & INT & 2 & \\
\hline 4 & tidak & Tidak & INT & 2 & \\
\hline 5 & Pykya & Pykya & INT & 2 & \\
\hline 6 & Pyk tidak & pyktidak & INT & 2 & \\
\hline
\end{tabular}

Berikut adalah tampilan database pakar.db dari tabel gejala :

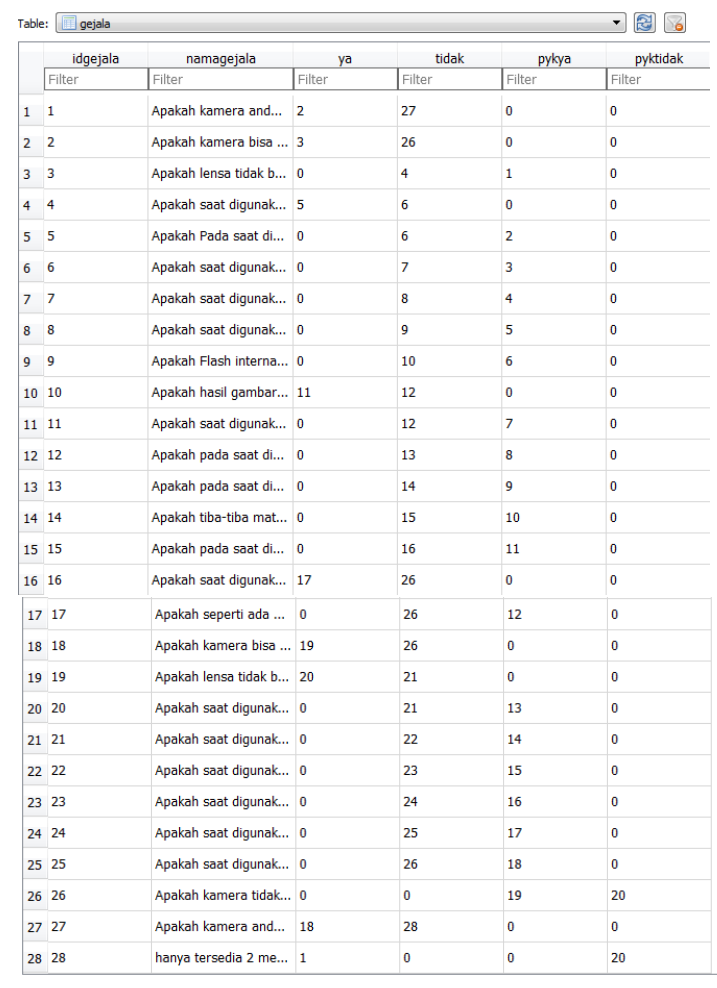

Gambar 4. Tampilan Tabel Gejala

Tabel 2. Tabel Kerusakan 


\begin{tabular}{|c|c|c|c|c|c|}
\hline $\begin{array}{l}\mathrm{N} \\
\mathrm{o}\end{array}$ & $\begin{array}{l}\text { Elemen } \\
\text { Data }\end{array}$ & Akronim & $\begin{array}{c}\text { Tip } \\
\text { e }\end{array}$ & $\begin{array}{l}\text { Pan } \\
\text { jan }\end{array}$ & $\begin{array}{c}\text { Keteran } \\
\text { gan }\end{array}$ \\
\hline 1 & $\begin{array}{l}\text { Id } \\
\text { Kerusakan }\end{array}$ & $\begin{array}{l}\text { idkerusaka } \\
\mathrm{n}\end{array}$ & INT & 2 & $\begin{array}{l}\text { Primary } \\
\text { Key }\end{array}$ \\
\hline 2 & $\begin{array}{l}\text { Nama } \\
\text { Kerusakan }\end{array}$ & $\begin{array}{l}\text { namakerus } \\
\text { akan }\end{array}$ & $\begin{array}{l}\text { TE } \\
\text { XT }\end{array}$ & 97 & \\
\hline
\end{tabular}

Berikut adalah tampilan database pakar.db dari tabel kerusakan:

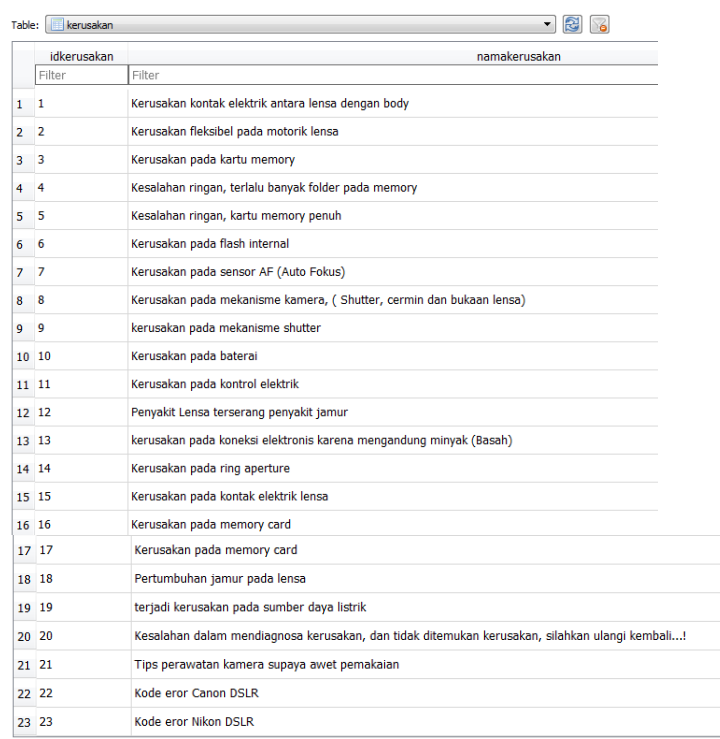

Gambar 5. Tampilan Tabel Kerusakan

Proses pembacaan dari tabel gejala pada database diatas menggunakan metode forward chaining sebagai berikut :

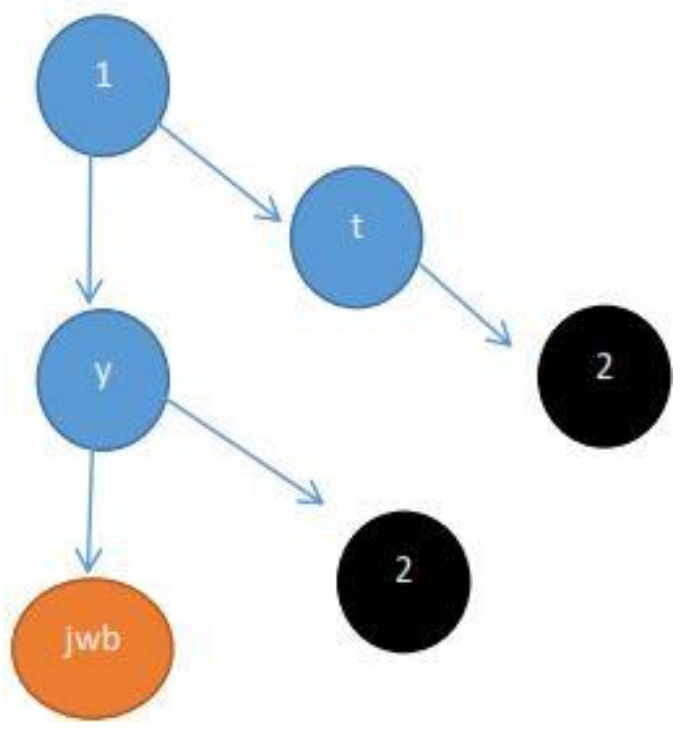

Gambar 5. Metode Forward Chaining

Keterangan:

Dari gambar diatas adalah cara aplikasi membaca gejala dengan metode forward chaining yang dimulai dari nomor satu pada daftar kerusakan nomor satu, apabila pengguna memilih "ya" maka aplikasi akan membaca dan masuk kedalam daftar urut gejala pada kerusakan nomor satu, tetapi apabila mengklik "tidak" maka aplikasi akan membaca melompati daftar gejala tadi dan membacakan gejala kerusakan kedua. Implementasi pada sistem untuk mendiagnosa kerusakan digambarkan dengan menggunakan flowchart yang ada sebagai berikut :

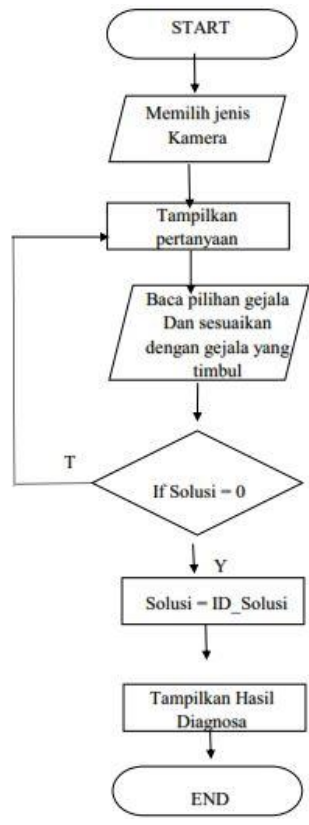

Gambar 7. Flowchart

Berikut adalah hasil tampilan atau layout sistem pakar diagnosa kamera dslr yang sudah dirancang oleh penulis:

Nama Dokumen : Diagnosa kerusakan

Fungsi : Memberikan pertanyaan seputar gejala kerusakan

Tujuan : Mendiagnosa permasalahan pada kamera dslr

Media : Layout (Web View)

Jumlah $\quad: 1$

Frekuensi : Akan muncul saat pengguna mengklik menu diagnosa 


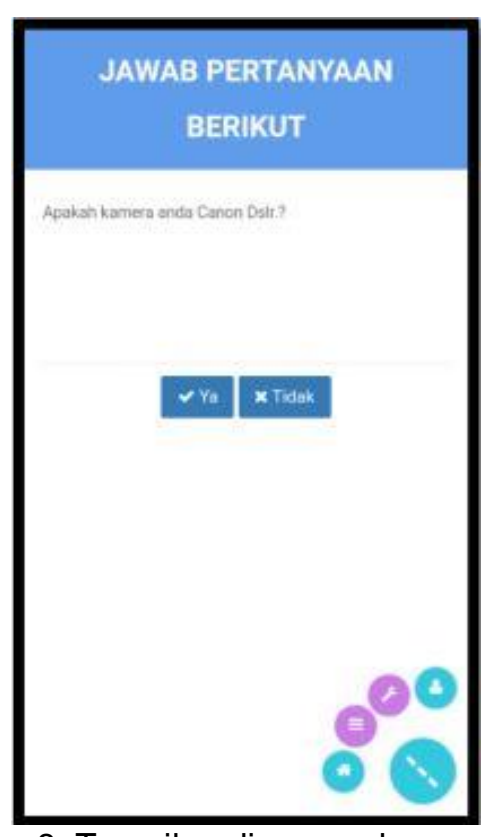

Gambar 8. Tampilan diagnosa kerusakan

Nama Dokumen : Informasi Kerusakan Fungsi : Pengguna memilih jenis kerusakan yang telah disediakan

Tujuan : Menampilkan jenis kerusakan yang tersedia di list database

Media $\quad: \quad$ Layout (Web View)Jumlah $: 1$

Frekuensi : Akan muncul saat pengguna mengklik menu informasi

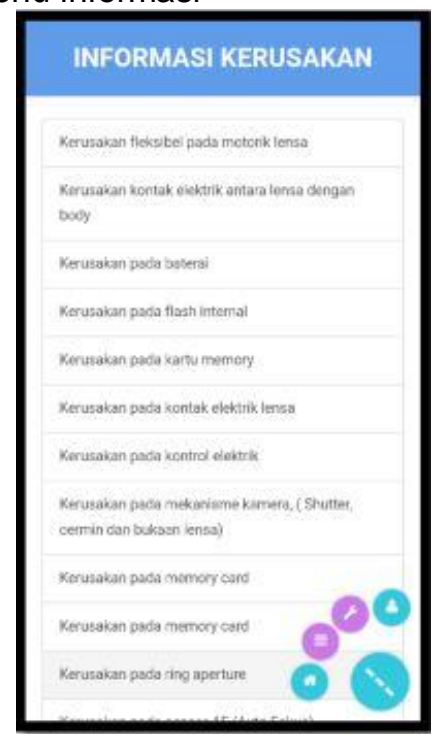

Gambar 9. Tampilan informasi kerusakan

\section{E. KESIMPULAN}

Setelah mempelajari, membahas dan menganalisa pengetahuan sistem pakar diagnosa kerusakan kamera ds/r, penulis menyimpulkan :

1. Aplikasi sistem pakar ini mampu membantu penggunaan secara umum dan dapat mendiagnosa jenis kerusakan kamera dsIr yang berbasis android.
2. Aplikasi sistem pakar ini memberikan keluaran berupa deskripsi kerusakan dan solusi kerusakan kamera secara teknis.

3. Tampilan yang digunakan dalam aplikasi mudah dipahami oleh pengguna.

4. Aplikasi ini dapat dibawa kemana saja karena aplikasi yang dibuat berbasis android sehingga lebih mudah dibawa kemana saja.

5. Aplikasi ini bisa berjalan dengan baik pada android 5.1, processor quad core, ram $1 \mathrm{~GB}$.

\section{DAFTAR PUSTAKA}

[1] Abdulloh, Syukri. (2012, Maret 27). Program Komputer. Dipetik Agustus 22, 2017, dari http://www.itartikel.com:

http://www.itartikel.com/2012/03/programkomputer.html

[2] Anywhere Software, B4A. (2017.). Basic For Android. Dipetik september 04, 2017, dari https://www.b4x.com/b4a.html\#documentati on.

[3] Browser, SQLite. (t.thn.). DB For SQLite. Dipetik september 27, 2017, dari http://sqlitebrowser.org/:http://sqlitebrowser. org/

[4] C, Antonius. Rachmat. (2010). Algoritma dan Pemrograman dengan Bahasa CKonsep, Teori \& Implmentasi.Yogyakarta: Andi Offset.

[5] Edmunds, R. (2015, Agustus 10) Troublesooting Brackets. Dipetik september 03, 2017, dari https://github.com/adobe/brackets/wiki/Trou bleshooting

[6] Fatta, Hanif. Al. (2007). Analisa dan Perancangan Sistem Informasi untuk Keunggulan Bersaing Perusahaan dan Organisasi Modern. Yogyakarta: Andi Offset.

[7] Hayadi, B. H. (2016). Dalam Sistem Pakar. Yograkarta: Deepublish.

[8] Kowi, E. M. (2016). Dalam Dasar-Dasar Pemrogaman Pascal. Jakarta: Guepedia.

[9] Kusnadi. (2008). Sistem Operasi. Yogyakarta: Andi Offset.

[10] Rosnelly, Rika. (2012). Sistem PakarKonsep dan Teori. Yogyakarta: Andi Offset.

[11] Salbino, S. (2014). android. Dalam Buku Pintar Gadget Android untukPemula. Jakarta: Kunci Komunikasi.

[12] S, Stephanus. Hermawan. (2011). Mudah Membuat Aplikasi Android. Yogyakarta: Andi Offset.

[13] Suarga. (2012). Algoritma Pemrograman. Yogyakarta: Andi Offset.

[14] Sutabri, Tata. (2012). Analisa Sistem Informasi. Yogyakarta: Andi Offset. 
[15] Wahadyo, A. (2013). Dalam Android 4 untuk Pengguna Pemula Tablet dan Handphone. Jakarta: Mediakita. 